OPEN ACCESS

Edited by:

Shuyang Zhang

Peking Union Medical College Hospital, China

Reviewed by:

Ronald J. Vagnozzi.

Cincinnati Children's Hospital Medical

Center, United States

Xiang Xie,

Xinjiang Medical University, China

*Correspondence:

Qing Yang

cardio-yq@tmu.edu.cn

Xin Zhou

xinzhou@tmu.edu.cn

Specialty section:

This article was submitted to

General Cardiovascular Medicine,

a section of the journal

Frontiers in Cardiovascular Medicine

Received: 27 August 2020 Accepted: 10 December 2020

Published: 18 January 2021

Citation:

Liu H, Wang Z, Sun H, Teng T, LiY,

Zhou X and Yang Q (2021)

Thrombosis and Coagulopathy in COVID-19: Current Understanding and Implications for Antithrombotic

Treatment in Patients Treated With

Percutaneous Coronary Intervention.

Front. Cardiovasc. Med. 7:599334.

doi: 10.3389/fcvm.2020.599334

\section{Thrombosis and Coagulopathy in COVID-19: Current Understanding and Implications for Antithrombotic Treatment in Patients Treated With Percutaneous Coronary Intervention}

\author{
Hangkuan Liu ${ }^{1,2}$, Zhijia Wang ${ }^{1,2}$, Haonan Sun ${ }^{1,2}$, Tianming Teng ${ }^{2}$, Yongle $L^{2}{ }^{2}$, Xin Zhou ${ }^{2 *}$ \\ and Qing Yang ${ }^{2 *}$ \\ ${ }^{1}$ Graduate School of Tianjin Medical University, Tianjin, China, ${ }^{2}$ Department of Cardiology, Tianjin Medical University General \\ Hospital, Tianjin, China
}

Coronavirus disease 2019 (COVID-19), a respiratory syndrome, is a global pandemic. Therefore, there is an urgent need to explore mechanisms implicated in the pathogenesis of the disease. Clinical and autopsy studies show a complex chain of events preceding COVID-19-related death. The disease is characterized by endothelial dysfunction, platelet activation, thrombosis, coagulopathy, and multiple organ failure. Globally, millions of patients with coronary heart disease undergo percutaneous coronary intervention (PCl) each year. These patients undergo high-intensity antithrombotic therapy during hospitalization and dual antiplatelet therapy (DAPT) for at least 6 months post PCl. COVID-19 is characterized by changes in platelet counts. Treatment of ischemic events that occur during stent implantation is associated with bleeding complications in patients following $\mathrm{PCl}$ complicated by COVID-19. This review summarizes recent progress in activation status and levels of COVID-19-related platelet changes. These findings will provide information on the effectiveness of antithrombotic therapy for the management of platelet changes in COVID-19 patients.

Keywords: COVID-19, thrombosis, coagulopathy, antithrombotic treatment, percutaneous coronary intervention

\section{INTRODUCTION}

Coronavirus disease 2019 (COVID-19), a severe acute respiratory syndrome coronavirus 2 (SARS-CoV-2) infection, is a worldwide pandemic. In November 2020, the World Health Organization reported over 50 million confirmed cases of COVID-19 and 1.3 million deaths globally (1). COVID-19 is associated with pneumonia and a wide range of effects on the cardiovascular system, thus, it is a health and economic burden worldwide (2-5).

SARS-CoV-2 enters host cells through coupling of viral spike protein and angiotensin-converting enzyme 2 (ACE-2) on the surface of host cells $(6,7)$, in a similar way as observed during SARS-CoV infection (8). Previous autopsy evaluations of SARS-infected patients (9) and recent clinical trials on COVID-19 patients $(10,11)$ show that diffuse alveolar injury and development of acute respiratory distress syndrome (ARDS) are the main pulmonary pathological manifestations. Cardiovascular effects, especially venous thromboembolic disease $(12,13)$ and 
ischemic complications in arterial system, such as ischemic stroke (14), have been reported in COVID-19 patients.

A recent study reports significant changes in platelet gene expression and function in COVID-19 patients. These changes result in platelet activation and aggregation, which are potential novel mechanisms for management of COVID-19-associated thrombosis and coagulopathy (15). Notably, severe COVID-19 cases present with thrombocytopenia (16), which is associated with platelet depletion and a high risk of bleeding. Approximately 5 million percutaneous coronary interventions (PCIs) are performed each year worldwide (17). Therefore, COVID-19 patients requiring antithrombotic therapy have a high risk of thrombotic events and bleeding complications (16). Hence, in this review, we explored recent studies reporting relationships between changes in platelet function and coagulopathy in COVID-19 patients. The findings of this study will provide a mechanistic basis for designing new treatment approaches for thrombosis and coagulopathy in COVID-19 patients. Further, this study provides information for the development of personalized antithrombotic therapy regimen for COVID-19 patients treated with PCI.

\section{CLINICAL CHARACTERISTICS OF COVID-19 PATIENTS}

A previous clinical trial reports that the prevalence of hypertension, diabetes, and coronary heart disease among COVID-19 patients in the first 2 months of the outbreak was $15,7.4$, and $2.5 \%$, respectively (18). Prevalence of hypertension, diabetes, and coronary heart disease significantly increased to $35.8,26.9$, and $9.0 \%$, respectively, for patients who were admitted in intensive care units receiving mechanical ventilation or patients who succumbed to the disease (18). In a study carried out at Mount Sinai Hospital, comorbidity with hypertension (62.7\%), diabetes mellitus (40.3\%), coronary artery disease (31.3\%), chronic kidney disease (26.7\%), and asthma (17.9\%) was higher in patients who succumbed to COVID-19 compared with that of survivors (19). Notably, thrombocytopenia (defined as a platelet count of $<150,000 / \mu \mathrm{l}$ ) was observed in $36.2 \%$ patients on admission, mainly in patients with severe cases (18). Moreover, prolonged prothrombin time and elevated D-dimer level, which indicated coagulopathy associated with COVID-19, were mainly reported in severe cases $(3,18,20)$.

SARS-CoV-2 is a new coronavirus strain that belongs to the same class with SARS reported in 2003 (21). Clinical studies on SARS patients reported an increase in activated partial thromboplastin time (42.8\%), thrombocytopenia (44.8\%), and elevated D-dimer (45.0\%) (22). In addition, a previous study reports thrombocytopenia in SARS patients (55\%), increase in activated partial thromboplastin time (63\%) and

Abbreviations: ACS, acute coronary syndrome; ARDS, acute respiratory distress syndrome; COVID-19, coronavirus disease 2019; DAPT, dual antiplatelet therapy; DIC, disseminated intravascular coagulation; IL-6, interleukin-6; MOF, multiple organ failure; PCI, percutaneous coronary intervention; SARS-CoV-2, severe acute respiratory syndrome coronavirus 2; STEMI, ST-segment elevation myocardial infarction. disseminated intravascular coagulation (DIC, 2.5\%) (23). Clinical manifestations observed in SARS-CoV- and SARS-CoV2 -infected patients indicate a high risk of DIC. Therefore, World Health Organization interim guidance statement recommends prophylactic administration of low-molecular-weight heparin daily or subcutaneous administration of unfractionated heparin 2 times in a day (24). In addition, American College of Cardiology recommends that patients should receive all scheduled doses of venous thromboembolism prophylaxis (25). Administration of low-molecular-weight heparin daily is preferred over unfractionated heparin, as it reduces personal protective equipment use and exposure of health care workers (25).

\section{BRIEF SUMMARY OF VIRAL PNEUMONIA PATHOLOGY}

Viral pneumonia accounts for one third of adult communityacquired pneumonia. Most viral pneumonia cases are caused by influenza, rhinovirus, and coronavirus infections (26). Viral pneumonia is characterized by histopathological changes including interstitial pneumonitis with lymphocytic infiltrations. Other manifestations such as necrotizing bronchiolitis, diffuse alveolar injury with alveolar hemorrhage, alveolar septal edema, and hyaline-membrane formation may be present depending on conditions associated with co-infection and underlying disease (26).

\section{Lung Pathology of Severe Acute Respiratory Syndrome}

During 2002 and 2003, the SARS-CoV caused severe respiratory infection in more than 8,000 people and led to 774 deaths, with a mortality rate of $9.6 \%$ (27). The typical pathological change in SARS-infected lungs was diffuse hemorrhage on the lung surface and serous, fibrinous, and hemorrhagic inflammation in most pulmonary alveoli (9). In addition to diffuse alveolar hemorrhage, other commonly observed findings were the presence of intraartery fibrin thrombi $(5 / 8)$ and intra-alveolar hemorrhage (6/8) (28).

\section{Lung Pathology and Multiple Organ Failure in Coronavirus Disease 2019}

The early pulmonary pathological changes in SARS-CoV2infected lungs included edema, proteinaceous exudate, and focal reactive hyperplasia of pneumocytes with patchy inflammatory cellular infiltration, whereas hyaline membranes were not prominent (29). The key features of lung pathology from severe COVID-19 patients were bilateral diffuse alveolar injury with cellular fibromyxoid exudates, as well as hyaline membrane formation (11). Other pathological findings included the presence of inflammatory lesions (gray-white lesions), dark red bleeding lesions, and sticky secretions in the lung tissue (10) and severe alveolar edema and hemorrhagic necrosis in both lungs, along with extensive pulmonary interstitial fibrosis and partial hyaline degeneration (30). These findings provided clear evidence for diffuse alveolar injury in severe COVID-19 cases. 
There have been accumulating pathologic findings of COVID-19 outside China (12, 31-34). Diffuse alveolar injury, endothelial injury, thromboembolism, and viral particles within renal cells were reported in various COVID-19 cases (12). A case series from Washington State showed that coronaviruslike particles were detected in the respiratory system, kidney, and gastrointestinal tract (32). Additionally, in one patient complicated by myocarditis, the viral RNA could be detected in the heart as well (32). More recent findings suggest that COVID19 may be a complex infection associated with extensive vascular endotheliitis $(33,34)$, manifesting an imbalance between the coagulation and immune functions in the body, which would pose the infected individual at risk for developing multiple organ failure (MOF).

It should be noted that the above pathological findings are mainly the direct and indirect consequences of lung tissue destruction induced by intracellular viral proliferation. In the rapid progressive and life-threatening form of viral pneumonia, the underlying pathological process is often diffuse alveolar injury, coagulopathy, and MOF (26). Collectively, these findings revealed a mechanistic link between virus infection, proliferation, and diffuse alveolar injury (35): the pathologic change evolves from alveolar capillary dysfunction and platelet activation, followed by intravascular fibrin and micro-thrombus formation; if left uncontrolled, these alterations would trigger systemic dissemination and secondary fibrinolysis and result in platelet and coagulation factor depletion and consequently lead to DIC, even MOF.

\section{NEW MECHANISMS UNDERLYING THROMBOSIS AND COAGULOPATHY IN COVID-19}

Replication and dissemination of SARS-CoV-2 in systemic circulation lead to extrapulmonary manifestations, which play key roles in disease progression $(2,34,36)$. A previous German prospective cohort study reports a high incidence of deep venous thrombosis (58\%) and diffuse alveolar injury (67\%) (12). These manifestations are associated with enhanced inflammatory state and hypercoagulable state, resulting in higher rates of venous and arterial thrombosis $(12,37)$. Moreover, increased severe bleeding rates are reported in critically ill patients following preventive or therapeutic anticoagulant and antiplatelet therapy (37). Subsequent sections of this review will summarize mechanisms involved in the pathogenesis of thrombosis and coagulopathy in COVID-19 patients as a complex chain of pathophysiological events preceding COVID-19-related death (summarized in Figure 1).

\section{Endothelial Dysfunction}

Endothelial dysfunction induces inflammation and vascular remodeling (38), which are associated with severe COVID19. Endotheliopathy or endothelial dysfunction, including endothelial activation, endotheliitis, and thrombotic events, is an indicator of coagulopathy in COVID-19 patients $(33,34,39)$.
SARS-CoV-2 enters host cells by binding to ACE-2 on pulmonary epithelial cells resulting in lung damage $(6,7)$. Moreover, vascular endothelial cells of multiple organs, including kidney, heart, and small bowel are infected by SARS-CoV2 directly. Infection induces apoptosis and pyroptosis, which result in diffuse endothelial inflammation (40). Upregulation of vascular endothelial growth factor and downregulation of Ecadherin expression enhance the permeability of endothelial cells in COVID-19 patients (41). In addition, biopsy of lung tissues of COVID-19 patients shows upregulation of interleukin-6 (IL-6), tumor necrosis factor- $\alpha$, intercellular adhesion molecule-1, and caspase-1 expression (39). Further, quantitative analysis showed a significant increase in expression levels of von Willebrand factor antigen and soluble P-selectin, which are markers of endothelial cell and platelet activation, in COVID-19 patients admitted to intensive care units (34). Notably, increased expression levels of von Willebrand factor antigen and soluble P-selectin are correlated with mortality (34). Increases in expression levels of these markers imply that endotheliopathy is implicated in the pathogenesis of COVID-19.

\section{Platelet Activation and Depletion}

A previous study reports that lungs have a high hematopoietic potential, thus they contribute to terminal platelet production (nearly 50\%) (42). Therefore, the platelet-related response in COVID-19 patients may be more rapid and severe during the initial stage of pulmonary infection. In addition to thrombosis and hemostasis, previous studies report a putative role of platelets in host defense against infections (43-45). A previous study using a mouse model reports that platelets migrate to the microvasculature (46). Migratory phenotype contributes to mechano-scavenging and bundling of bacteria and boosts innate immunity in a mouse model of severe bacteremia (46). Moreover, human and murine platelets are induced by a range of antimicrobial compounds, especially platelet microbicidal proteins to exert direct microbicidal activity (43). These findings make it challenging to interpret the impact of platelet activation and depletion in COVID-19 patients. Reports from observational studies during the early days of the outbreak in China and other countries show a significant change of platelet response (from excessive activation to depletion) during the progression of severe COVID-19 cases $(15,47)$.

At the early phase of infection, SARS-CoV-2 invades the lung tissue of the host, which may activate platelets through changes in gene expression $(15,42)$. Platelets detect invading pathogens through a broad array of receptors and elicit interaction with immune cells (neutrophils, monocytes, and lymphocytes) (15). Activated platelets then exhibit an augmented aggregation capacity by upregulating membrane Pselectin level, which enhances interactions and aggregation with neutrophils, monocytes, and T cells, through mitogen-activated protein kinase (MAPK) pathway activation and thromboxane generation (15).

Lungs and bone marrow are the main sources of compensatory production of platelet consumption in a variety of thromboembolic disorders (42). During infection, neutrophil extracellular trap formation, platelet aggregation, 


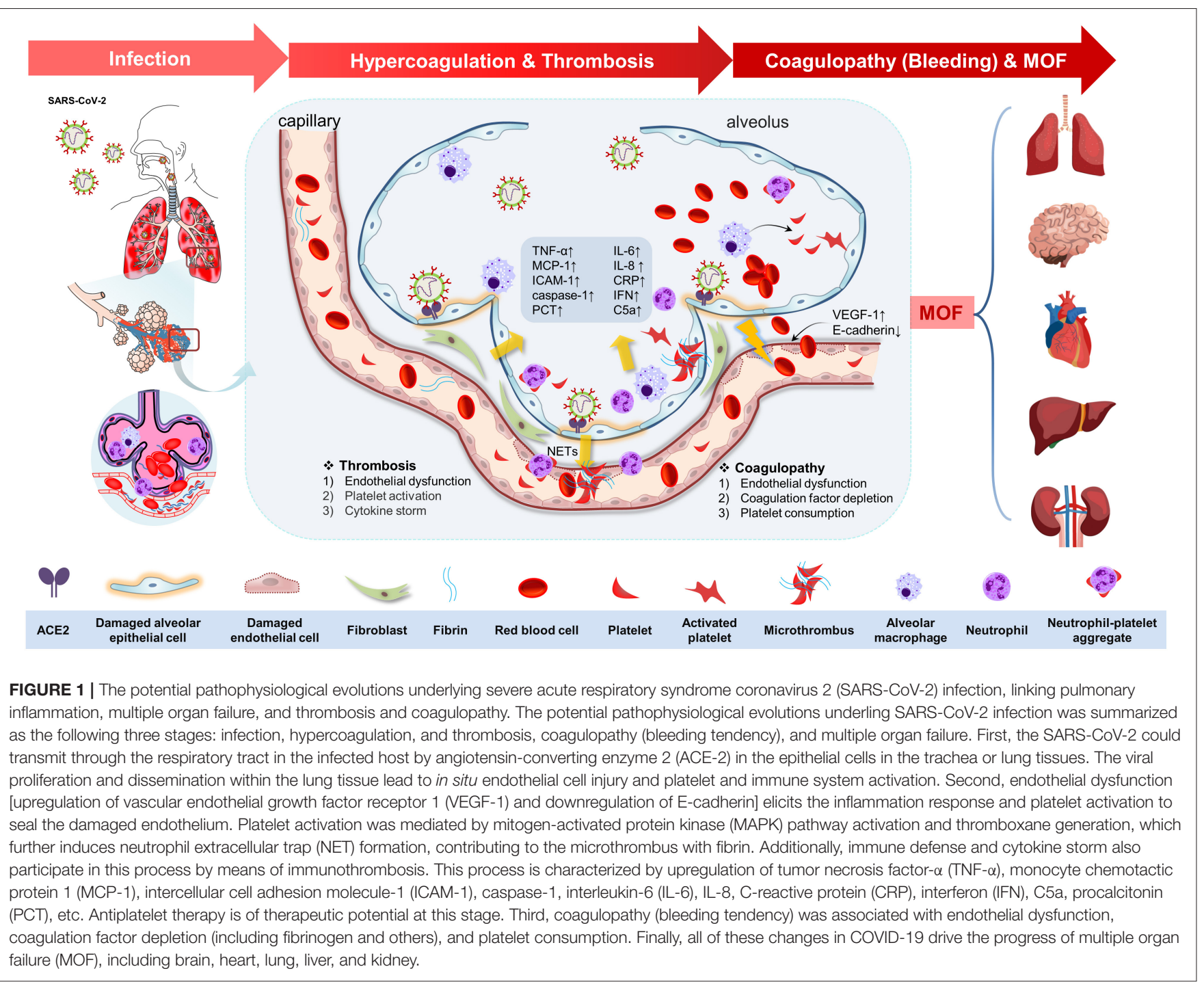

and microthrombus formation reduce tissue perfusion and aggravate inflammation and endothelial injury by activating leukocyte signaling (48). A previous study showed that a high bleeding rate in critically ill COVID-19 patients (7.6 vs. 3.1\%) was positively correlated with peak D-dimer levels and negatively correlated with platelet counts (49). Replenishment of circulating platelets is a fine-tuned process determined by the dynamic balance between platelet consumption and production. In severe pulmonary inflammatory response, such as SARS and COVID19 cases, virus proliferation and dissemination within the lung tissue may directly contribute to in situ activation of lung megakaryocyte-derived platelets or have a direct impact on lung megakaryocytes. This may lead to changes in gene expression profile of platelets as observed in COVID-19 patients (15). If this response is not resolved within the lung tissue, platelet activation and ensuring microthrombus formation in lung vasculature would further aggravate pulmonary inflammation. Systemic endothelitis caused by dissemination of SARS-CoV-2 then elicits a second wave of platelet activation in extrapulmonary organs. The second wave leads to a more severe form of platelet activation resulting in consumptive thrombocytopenia (18). Therefore, there is a critical transition in which the beneficial effect of antiplatelet therapy at an early stage of COVID-19 can be attenuated or may have severe effects by aggravating bleeding when clinically significant thrombocytopenia develops.

\section{Immune Defense and Cytokine Storms}

Activation of the immune system, which includes production of cytokines, immune complements, and various immune cells, plays an important role in fighting SARS-CoV-2 infection (41). Immune response is always a double-edged sword. Under inflammatory conditions in COVID-19 patients, immunothrombosis, which contains invading pathogens driven by platelets, neutrophils, and the coagulation cascade, is a central pathogenic factor linking respiratory failure and systemic hypercoagulation (50). In addition, immunothrombosis leads to vessel occlusion and tissue hypoxia, which may enhance 
the inflammatory response. COVID-19 patients with loss-offunction variants of Toll-like receptor 7 , which mediates type I interferon and interferon- $\gamma$ production, show poor prognosis and subtle subsegmental pulmonary embolisms (51). These findings imply that the immune system is closely associated with thrombosis during SARS-CoV-2 infection.

Recent studies report that the serum of COVID-19 patients showed elevated cytokine levels (C-reactive protein, IL-6, IL-8, and monocyte chemotactic protein-1) (41), high complement levels (C5a) (52), and reduced lymphocyte counts (41). The negative correlation between high levels of IL-6 or IL-8 and low lymphocyte counts indicates underlying mechanisms that link these characteristics in severe disease, including immunothrombosis. This finding is consistent with reports that treatment of COVID-19 patients with tocilizumab, which blocks IL-6-mediated signaling, restored circulating levels of lymphocytes to levels close to normal ranges (53). Enhanced host immune response plays a pivotal role in inducing MOF. Therefore, the efficacy of dexamethasone, a nonspecific immunosuppressant, was evaluated in a large randomized clinical trial and a meta-analysis in patients hospitalized with COVID-19 (54, 55). The results showed approximately 30\% reduction in mortality for patients under respiratory support. Therefore, these findings imply that excessively activated host immune response aggravates COVID-19-associated MOF.

\section{ANTITHROMBOTIC THERAPY IN COVID-19 PATIENTS TREATED WITH PERCUTANEOUS CORONARY INTERVENTION}

During the COVID-19 global pandemic lockdown period, the number of patients presenting with acute coronary syndrome (ACS) and emergency coronary procedures reduced significantly in Europe (56-58), the USA $(59,60)$, and Asia (61). However, ACS patients were the main target population among patients with coronary heart disease in cardiology departments during the COVID-19 epidemic compared with patients with chronic coronary syndrome (62). At the beginning of the COVID19 outbreak, the number of admitted ACS patients in most world regions significantly reduced. Clinical management of ACS during this period was characterized by a decrease in hospitalization rate $[-48.4 \%$ in Italy (57)], a decrease in PCI rate $[-24 \%$ in China $(61),-43 \%$ in Hubei $(61),-32 \%$ in Italy (63)], and an increase in thrombolytic rate $[+66 \%$ in China (61), $+378 \%$ in Hubei (61)]. A recent study in UK showed that a reduction in ACS hospitalization by $40 \%$ from the initial days of the COVID-19 outbreak was gradually decreasing to a $16 \%$ reduction in May 2020 (64). The number of PCI procedures decreased in both ST-segment elevation myocardial infarction (STEMI) and non-STEMI patients $(-21$ and $-37 \%$, respectively) (64). Furthermore, STEMI patients with COVID19 showed a higher thrombus load, with $17.9 \%$ of these patients presenting with multiple thrombus formation (65). In addition to ensuring timely and effective revascularization of ACS patients (especially STEMI patients), the control of COVID-19 infection in ACS patients is important. Different countries have different views on treatment approaches of ACS patients coinfected with COVID-19 (66-73). Therefore, there is a need to explore appropriate treatment measures for ACS patients during the COVID-19 epidemic.

\section{Coronavirus Disease 2019-Related Delay: The Dilemma for Pre-hospital Management of Acute Coronary Syndrome}

Early diagnosis and timely management are critical in reducing morbidity and mortality related to ACS. Ischemic time duration is a major determinant of infarct size in patients with STEMI. Current delays in COVID-19 testing, termed as "COVID-19related delay," may contribute to total ischemia time (74). Tam et al. (75) reported that median pre-hospital delay increased from 82.5 to $318 \mathrm{~min}$ and door to device time increased from 84.5 to $110 \mathrm{~min}$.

\section{Primary Percutaneous Coronary Intervention or Thrombolysis: The Choice of Optimal In-hospital Treatment of Acute Coronary Syndrome}

Recent studies showed that patients with STEMI presenting with concurrent COVID-19 present with unique findings during coronary angiography $(65,76)$. A study carried out in Italy reports that 11 patients (39.3\%) out of 28 COVID-19 patients admitted for STEMI showed no obstructive coronary artery disease (76). Another single-center study from UK comprising 115 consecutive STEMI patients with confirmed concurrent COVID-19 reported significantly higher rates of multivessel thrombosis, stent thrombosis, and glycoprotein IIb/IIIa inhibitor use (65). Notably, these findings were based on small observational studies. However, angiographic manifestations require a dedicated diagnostic approach and a modified antithrombotic regimen for this special population.

While primary PCI remains the treatment of choice for STEMI, the balance between exposure risk of medical staff and benefit of patient from thrombolysis should be considered in certain circumstances. Strategic Reperfusion Early After Myocardial Infarction study demonstrated that even a single hour of delay may affect the effectiveness of primary PCI compared with thrombolysis (77).

In China and Iran, thrombolytic therapy is recommended over primary PCI for STEMI management if COVID-19 was confirmed or could not be excluded within a short time. On the other hand, SARS-CoV-2 infection is excluded first for non-STEMI and unstable angina pectoris approaches (66-69). Conversely, organizations from the United States (72), Europe (73), Australia, and New Zealand (70) recommend the use of existing primary PCI protocols for STEMI patients except for confirmed COVID-19 patients and persons under investigation or cases in which primary PCI could not be performed within required time frames. Moreover, previous studies recommend that coronary angiography should be performed prior to discharge after the patient has stabilized from COVID-19 (78). 


\section{Periprocedural Anticoagulant Therapy: Intensified and Prolonged}

A high risk of thrombotic complications in patients with COVID-19 complicates the dosage of anticoagulation in hospitalized patients with COVID-19 (25). Anticoagulation is recommended for patients with thrombotic complications in addition to antiplatelet therapy during primary PCI $(79,80)$. In addition, routine use of unfractionated heparin (I, C) and enoxaparin intravenous (IIa, A) should be considered (79). In patients with heparin-induced thrombocytopenia, bivalirudin is recommended as an anticoagulant agent during primary PCI (I, C) (79). The optimal dosage of anticoagulants (conservative or radical) in COVID-19 patients should be personalized based on inflammatory state and a hypercoagulable state of the patients.

The 2018 European Society of Cardiology guideline does not give guidelines on routine post-procedural anticoagulant therapy after primary PCI (79). STEMI patients should receive at least $48 \mathrm{~h}$ of anticoagulation therapy after intravenous thrombolysis (80). Introduction of post-procedural anticoagulation and prolongation of anticoagulation therapy is required to counterbalance the COVID-19-related systemic hypercoagulability after primary PCI and intravenous thrombolysis for COVID-19 patients. Notably, these therapy approaches may increase the risk of heparin-induced thrombocytopenia (81).

\section{Dual Antiplatelet Therapy: The Choice of Optimal P2Y 12 Inhibitor}

In a previous prospective study, our group summarized reports on thrombotic and bleeding incidence from early findings of COVID-19 outbreak and reported on the pros and cons of antithrombotic treatment for patients following PCI (16). The findings from this review add more information on the use of antithrombotic treatment in COVID-19 patients. Notably, the time of initiating an antithrombotic regimen should be considered. In the early phase of COVID-19, platelet inhibition by dual antiplatelet therapy (DAPT) may suppress the hyperactivation state of platelets probably through inhibition of in situ platelet activation in lung vasculature $(15,42)$. Antiplatelet agents used at this stage affect intravascular fibrin and thrombus formation, thereby preventing secondary fibrinolysis and coagulation factor depletion. Notably, observational studies report that pre-hospitalization aspirin use is associated with lower mortality in patients with community-acquired pneumonia (100 mg) (82) and ARDS (75-300 mg) (83). On the contrary, findings from a randomized clinical trial show that aspirin administration after admission (325 mg loading followed by $81 \mathrm{mg}$ daily for 7 days) does not prevent the development of ARDS (84). In addition, the choice of antiplatelet agents with different intensity modulates the effectiveness of antithrombotic treatment. An observational study showed that pre-hospital exposure to clopidogrel is associated with an increased risk for community-acquired pneumonia (85). Most patients treated with clopidogrel would receive aspirin. Therefore, it is difficult to draw a conclusion that $\mathrm{P}_{2} \mathrm{Y}_{12}$ inhibitor is harmful in terms of pneumonia prevention. However, higher intensity of platelet inhibition may lead to the suppression of antimicrobial effect of platelets. Furthermore, discontinuation of aspirin 1 to 3 months after PCI with continued $\mathrm{P}_{2} \mathrm{Y}_{12}$ inhibitor monotherapy significantly reduces the risk of major bleeding by $40 \sim 50 \%$, with no increased risk of major adverse cardiovascular events, compared with traditional DAPT (86). Therefore, continued $\mathrm{P}_{2} \mathrm{Y}_{12}$ inhibitor monotherapy may be relatively safe after PCI in COVID-19 patients with a higher risk of bleeding. Ticagrelor, a unique $\mathrm{P}_{2} \mathrm{Y}_{12}$ inhibitor, has an additional target of inhibition, the equilibrative nucleoside transporter 1; therefore, it results in higher antiplatelet effects and antibacterial activity (87). Moreover, a clinical benefit of ticagrelor in the management of pneumonia by preventing sepsis complications and reducing lung injury was reported in the recent XANTHIPPE (Targeting Platelet-Leukocyte Aggregates in Pneumonia With Ticagrelor) trial (88) and PLATO study (89). Furthermore, clinicians should carefully evaluate platelet counts and levels of other hematological parameters when describing antiplatelet agents. Both primary (idiopathic thrombocytopenic purpura) and secondary thrombocytopenia (enhanced consumption) are associated with an increased risk of infection (including pneumonia) (90), poor outcomes associated with pneumonia $(91,92)$, and increased mortality for ARDS (93). Individuals who are thrombocytopenic lose the ability to deposit fibrinogen and fail to seal damaged pulmonary vasculature (94). Therefore, platelets are potential therapeutic targets to help predict the onset of ARDS. Currently, there are no available studies on prolongation and intensified antiplatelet therapy in reducing COVID-19-related thrombosis and MOF; therefore, antiplatelet therapy, especially ticagrelor, following PCI should be maintained. However, a study carried out on East Asian populations showed a significantly higher incidence of clinical bleeding in the ticagrelor group compared with that in the clopidogrel group (11.7 vs. 5.3\%; hazard ratio, 2.26; 95\% confidence interval, 1.34-3.79; $P=0.002$ ) (95). A recent study from the SWEDEHEART Registry reports that ticagrelor use among elderly ACS patients is associated with a higher risk of bleeding (hazard ratio, 1.48; 95\% confidence interval, 1.25-1.76) and death (hazard ratio, 1.17; 95\% confidence interval, 1.03-1.32) compared with the use of clopidogrel (96). Therefore, ticagrelor should not be prescribed to the elderly and East Asian populations. Moreover, the balance between platelet consumption and production, host immune response, and the fact that the clinical benefit of DAPT in the context of COVID-19 is dependent on the severity of the disease should be considered during treatment.

\section{Prognosis of Acute Coronary Syndrome Patients Presenting With Concurrent Coronavirus Disease 2019}

Currently, the long-term impact of COVID-19-related endothelial activation, hypercoagulability, microvascular thrombosis, and myocardial injury is not well-known (97). Previous studies report that multiple imaging techniques can accurately assess cardiovascular conditions in COVID-19 patients (98-101). Cardiac nuclear magnetic resonance in 
patients recovering from COVID-19 infection shows myocardial involvement (mainly myocarditis, including myocardial edema, fibrosis, and impaired right ventricular function) (99-101). Interestingly, a 12-year follow-up survey of 25 patients who recovered from SARS-CoV infection showed that $68 \%$ of these patients had hyperlipidemia, $44 \%$ had cardiovascular system abnormalities, and $60 \%$ had glucose metabolism disorders (102). SARS-CoV-2 and SARS-CoV mechanism of infection and systemic involvements are similar; therefore, long-term prognosis of COVID-19 patients should be explored.

Zhang et al. (103) reported that in-hospital use of statins among 13,981 cases of COVID-19 was significantly associated with a lower risk of death (5.2 vs. 9.4\%, adjusted hazard ratio of 0.58 ) and less inflammatory response during the entire hospitalization period compared with non-statin use. This finding implies that statin plays a protective role in the acute management of COVID-19 by protecting vascular endothelium and regulating immunity (104).

\section{CONCLUSION}

Findings from clinical observations and autopsy studies show a complex chain of events preceding COVID-19-related death. The adverse event chain starts with viral infection and proliferation, followed by endothelial dysfunction induced by local and systemic viral dissemination. Further, platelet activation, thrombosis, and platelet and coagulation factor

\section{REFERENCES}

1. Word Health Organization. WHO Coronavirus Disease (COVID-19) Dashboard. WHO (2020). Available online at: https://covid19.who.int/

2. Nishiga M, Wang DW, Han Y, Lewis DB, Wu JC. COVID-19 and cardiovascular disease: from basic mechanisms to clinical perspectives. Nat Rev Cardiol. (2020) 17:543-58. doi: 10.1038/s41569-020-0413-9

3. Wang $\mathrm{D}, \mathrm{Hu} \mathrm{B}, \mathrm{Hu} \mathrm{C}$, Zhu F, Liu X, Zhang J, et al. Clinical Characteristics of 138 Hospitalized Patients With (2019). Novel Coronavirus-infected pneumonia in Wuhan, China. JAMA. (2020) 323:1061-9. doi: 10.1001/jama.2020.1585

4. Baldi E, Sechi GM, Mare C, Canevari F, Brancaglione A, Primi R, et al. Outof-hospital cardiac arrest during the Covid-19 outbreak in Italy. $N$ Engl $J$ Med. (2020) 383:496-8. doi: 10.1056/NEJMc2010418

5. Goyal P, Choi JJ, Pinheiro LC, Schenck EJ, Chen R, Jabri A, et al. Clinical characteristics of Covid-19 in New York city. N Engl J Med. (2020) 382:23724. doi: 10.1056/NEJMc2010419

6. Lu R, Zhao X, Li J, Niu P, Yang B, Wu H, et al. Genomic characterisation and epidemiology of 2019 novel coronavirus: implications for virus origins and receptor binding. Lancet. (2020) 395:565-74. doi: 10.1016/S0140-6736(20)30251-8

7. Hoffmann M, Kleine-Weber H, Schroeder S, Krüger N, Herrler T, Erichsen $\mathrm{S}$, et al. SARS-CoV-2 cell entry depends on ACE2 and TMPRSS2 and is blocked by a clinically proven protease inhibitor. Cell. (2020) 181:27180.e278. doi: 10.1016/j.cell.2020.02.052

8. Li F, Li W, Farzan M, Harrison SC. Structure of SARS coronavirus spike receptor-binding domain complexed with receptor. Science. (2005) 309:1864-8. doi: 10.1126/science.1116480

9. Lang ZW, Zhang LJ, Zhang SJ, Meng X, Li JQ, Song CZ, et al. A clinicopathological study of three cases of severe acute respiratory syndrome (SARS). Pathology. (2003) 35:526-31. doi: 10.1080/00313020310001619118 depletion occur leading to MOF and life-threatening bleeding. Patients treated with PCI and patients on antithrombotic treatment should undergo post-procedural anticoagulation and prolonged anticoagulation following intravenous thrombolysis and standard DAPT treatment to reduce the risk of thrombotic complications during early-to-mid stages of COVID-19 progression. Pros and cons of these antithrombotic treatment regimens should be evaluated in an individualized manner in cases of clinical thrombocytopenia (induced either by platelet consumption or by heparin) and/or bleeding complications.

\section{AUTHOR CONTRIBUTIONS}

HL and ZW performed the manuscript writing and illustration drawing. HS performed part of literature collecting. TT and YL provided critical scientific input and discussions. $\mathrm{XZ}$ and QY conceived, designed, and supervised all studies and the drafting and editing of the manuscript. All authors contributed to the article and approved the submitted version.

\section{FUNDING}

This work was supported by the National Natural Science Foundation of China (81970304) and Tianjin Municipal Science and Technology Commission (18ZXZNSY00290, 19JCQNJC11500, and 17JCZDJC34800).
10. Liu Q, Wang RS, Qu GQ, Wang YY, Liu P, Zhu YZ, et al. Gross examination report of a COVID-19 death autopsy. Fa Yi Xue Za Zhi. (2020) 36:213. doi: 10.12116/j.issn.1004-5619.2020.01.005

11. Xu Z, Shi L, Wang Y, Zhang J, Huang L, Zhang C, et al. Pathological findings of COVID-19 associated with acute respiratory distress syndrome. Lancet Respir Med. (2020) 8:420-2. doi: 10.1016/S2213-2600(20)30076-X

12. Wichmann D, Sperhake JP, Lütgehetmann M, Steurer S, Edler C, Heinemann A, et al. Autopsy findings and venous thromboembolism in patients with COVID-19. Ann Intern Med. (2020) 173:1030. doi: 10.7326/L20-1206

13. Zhang L, Feng X, Zhang D, Jiang C, Mei H, Wang J, et al. Deep vein thrombosis in hospitalized patients with COVID-19 in Wuhan, China: prevalence, risk factors, and outcome. Circulation. (2020) 142:11428. doi: 10.1161/CIR.0000000000000887

14. Li Y, Li M, Wang M, Zhou Y, Chang J, Xian Y, et al. Acute cerebrovascular disease following COVID-19: a single center, retrospective, observational study. Stroke Vasc Neurol. (2020) 5:279-84. doi: 10.1136/svn-2020-000431

15. Manne BK, Denorme F, Middleton EA, Portier I, Rowley JW, Stubben CJ, et al. Platelet gene expression and function in COVID-19 patients. Blood. (2020) 136:1317-29. doi: 10.1182/blood.2020007214

16. Zhou X, Li Y, Yang Q. Antiplatelet therapy after percutaneous coronary intervention in patients with COVID-19: implications from clinical features to pathologic findings. Circulation. (2020) 141:1736-8. doi: 10.1161/CIRCULATIONAHA.120.046988

17. Medmarket diligence. Global Dynamics of Surgical and Interventional Cardiovascular Procedures 2015-2022. Medmarket diligence (2018).

18. Guan WJ, Ni ZY, Hu Y, Liang WH, Ou CQ, He JX, et al. Clinical characteristics of Coronavirus disease 2019 in China. N Engl J Med. (2020) 382:1708-20. doi: 10.1056/NEJMoa2002032

19. Bryce C, Grimes Z, Pujadas E, Ahuja S, Beasley MB, Albrecht R, et al. Pathophysiology of SARS-CoV-2: targeting of endothelial cells renders a complex disease with thrombotic microangiopathy and aberrant immune 
response. The mount sinai COVID-19 autopsy experience. medRxiv [Preprint]. (2020). doi: 10.1101/2020.05.18.20099960

20. Zhou F, Yu T, Du R, Fan G, Liu Y, Liu Z, et al. Clinical course and risk factors for mortality of adult inpatients with COVID-19 in Wuhan, China: a retrospective cohort study. Lancet. (2020) 395:105462. doi: 10.1016/S0140-6736(20)30566-3

21. Cui J, Li F Shi ZL. Origin and evolution of pathogenic coronaviruses. Nat Rev Microbiol. (2019) 17:181-92. doi: 10.1038/s41579-018-0118-9

22. Lee N, Hui D, Wu A, Chan P, Cameron P, Joynt GM, et al. A major outbreak of severe acute respiratory syndrome in Hong Kong. N Engl J Med. (2003) 348:1986-94. doi: 10.1056/NEJMoa030685

23. Wong RS, Wu A, To KF, Lee $\mathrm{N}$, Lam CW, Wong CK, et al. Haematological manifestations in patients with severe acute respiratory syndrome: retrospective analysis. BMJ. (2003) 326:1358-62. doi: 10.1136/bmj.326.7403.1358

24. World Health Organization. Clinical Management of Severe Acute Respiratory Infection When Novel Coronavirus (2019-nCoV) Infection is Suspected. WHO (2020). Available online at: https://apps.who.int/iris/ handle/10665/332299

25. Bikdeli B, Madhavan MV, Jimenez D, Chuich T, Dreyfus I, Driggin E, et al. COVID-19 and thrombotic or thromboembolic disease: implications for prevention, antithrombotic therapy, and follow-up: JACC state-of-the-art review. J Am Coll Cardiol. (2020) 75:2950-73. doi: 10.1016/j.jacc.2020.04.031

26. Radigan KA, Wunderink RG. Epidemic viral pneumonia and other emerging pathogens. Clin Chest Med. (2011) 32:45167. doi: $10.1016 /$ j.ccm.2011.05.010

27. Word Health Organization. Summary of Probable Sars Cases With Onset of Illness From 1 November 2002 to 31 July 2003. WHO (2020). Available online at: https://www.who.int/csr/sars/country/table2004_04_21/en/

28. Franks TJ, Chong PY, Chui P, Galvin JR, Lourens RM, Reid AH, et al. Lung pathology of severe acute respiratory syndrome (SARS): a study of 8 autopsy cases from Singapore. Hum Pathol. (2003) 34:7438. doi: $10.1016 / \mathrm{S} 0046-8177(03) 00367-8$

29. Tian S, Hu W, Niu L, Liu H, Xu H Xiao SY. Pulmonary pathology of earlyphase 2019. Novel coronavirus (COVID-19) pneumonia in two patients with lung cancer. J Thorac Oncol. (2020) 15:700-4. doi: 10.1016/j.jtho.2020.02.010

30. Luo W, Yu H, Guo J. Clinical pathology of critical patient with novel coronavirus pneumonia (covid-19). Preprints [Preprint]. (2020). doi: 10.1097/TP.0000000000003412

31. Arentz M, Yim E, Klaff L, Lokhandwala S, Riedo FX, Chong M, et al. Characteristics and outcomes of 21 critically ill patients with COVID-19 in Washington state. JAMA. (2020) 323:1612-4. doi: 10.1001/jama.2020.4326

32. Bradley BT, Maioli H, Johnston R, Chaudhry I, Fink SL, Xu H, et al. Histopathology and ultrastructural findings of fatal COVID-19 infections in Washington State: a case series. Lancet. (2020) 396:32032. doi: 10.1016/S0140-6736(20)31305-2

33. Ackermann M, Verleden SE, Kuehnel M, Haverich A, Welte T, Laenger F, et al. Pulmonary vascular endothelialitis, thrombosis, and angiogenesis in Covid-19. N Engl J Med. (2020) 383:120-8. doi: 10.1056/NEJMoa2015432

34. Goshua G, Pine AB, Meizlish ML, Chang $\mathrm{CH}$, Zhang $\mathrm{H}$, Bahel $\mathrm{P}$, et al. Endotheliopathy in COVID-19-associated coagulopathy: evidence from a single-centre, cross-sectional study. Lancet Haematol. (2020) 7:e57582. doi: 10.1016/S2352-3026(20)30216-7

35. Taubenberger JK, Morens DM. The pathology of influenza virus infections. Annu Rev Pathol. (2008) 3:499522. doi: 10.1146/annurev.pathmechdis.3.121806.154316

36. Gupta A, Madhavan MV, Sehgal K, Nair N, Mahajan S, Sehrawat TS, et al. Extrapulmonary manifestations of COVID-19. Nat Med. (2020) 26:101732. doi: 10.1038/s41591-020-0968-3

37. Chan NC, Weitz JI. COVID-19 coagulopathy, thrombosis, and bleeding. Blood. (2020) 136:381-3. doi: 10.1182/blood.2020007335

38. Deanfield JE, Halcox JP, Rabelink TJ. Endothelial function and dysfunction: testing and clinical relevance. Circulation. (2007) 115:1285-95. doi: 10.1161/CIRCULATIONAHA.106.652859

39. Nagashima S, Mendes MC, Camargo Martins AP, Borges NH, Godoy TM, Miggiolaro A, et al. Endothelial dysfunction and thrombosis in patients with COVID-19. Arterioscler Thromb Vasc Biol. (2020) 40:24047. doi: 10.1161/ATVBAHA. 120.314860
40. Varga Z, Flammer AJ, Steiger P, Haberecker M, Andermatt R, Zinkernagel AS, et al. Endothelial cell infection and endotheliitis in COVID-19. Lancet. (2020) 395:1417-8. doi: 10.1016/S0140-6736(20) 30937-5

41. Moore JB, June CH. Cytokine release syndrome in severe COVID-19. Science. (2020) 368:473-4. doi: 10.1126/science.abb8925

42. Lefrançais E, Ortiz-Muñoz G, Caudrillier A, Mallavia B, Liu F, Sayah DM, et al. The lung is a site of platelet biogenesis and a reservoir for haematopoietic progenitors. Nature. (2017) 544:105-9. doi: 10.1038/nature21706

43. Nicolai L, Gaertner F, Massberg S. Platelets in host defense: experimental and clinical insights. Trends Immunol. (2019) 40:922-38. doi: 10.1016/j.it.2019.08.004

44. Ho-Tin-Noé B, Boulaftali Y, Camerer E. Platelets and vascular integrity: how platelets prevent bleeding in inflammation. Blood. (2018) 131:27788. doi: 10.1182/blood-2017-06-742676

45. Elzey BD, Tian J, Jensen RJ, Swanson AK, Lees JR, Lentz SR, et al. Platelet-mediated modulation of adaptive immunity. A communication link between innate and adaptive immune compartments. Immunity. (2003) 19:9-19. doi: 10.1016/S1074-7613(03)00177-8

46. Gaertner F, Ahmad Z, Rosenberger G, Fan S, Nicolai L, Busch B, et al. Migrating platelets are mechano-scavengers that collect and bundle bacteria. Cell. (2017) 171:1368-1382.e1323. doi: 10.1016/j.cell.2017.11.001

47. Huang C, Wang Y, Li X, Ren L, Zhao J, Hu Y, et al. Clinical features of patients infected with 2019 novel coronavirus in Wuhan, China. Lancet. (2020) 395:497-506. doi: 10.1016/S0140-6736(20)30183-5

48. Guo L, Rondina MT. The era of thromboinflammation: platelets are dynamic sensors and effector cells during infectious diseases. Front Immunol. (2019) 10:2204. doi: 10.3389/fimmu.2019.02204

49. Al-Samkari H, Karp Leaf RS, Dzik WH, Carlson JCT, Fogerty AE, Waheed A, et al. COVID-19 and coagulation: bleeding and thrombotic manifestations of SARS-CoV-2 infection. Blood. (2020) 136:489-500. doi: 10.1182/blood.2020006520

50. Nicolai L, Leunig A, Brambs S, Kaiser R, Weinberger T, Weigand M, et al. Immunothrombotic dysregulation in COVID-19 pneumonia is associated with respiratory failure and coagulopathy. Circulation. (2020) 142:117689. doi: 10.1161/CIRCULATIONAHA. 120.048488

51. van der Made CI, Simons A, Schuurs-Hoeijmakers J, van den Heuvel G, Mantere T, Kersten S, et al. Presence of genetic variants among young men with severe COVID-19. JAMA. (2020) 324:1-11. doi: 10.1001/jama.2020.13719

52. Shen B, Yi X, Sun Y, Bi X, Du J, Zhang C, et al. Proteomic and metabolomic characterization of COVID-19 patient sera. Cell. (2020) 182:59-72.e15. doi: 10.1016/j.cell.2020.05.032

53. Giamarellos-Bourboulis EJ, Netea MG, Rovina N, Akinosoglou K, Antoniadou A, Antonakos N, et al. Complex immune dysregulation in COVID-19 patients with severe respiratory failure. Cell Host Microbe. (2020) 27:992-1000.e1003. doi: 10.1016/j.chom.2020. 04.009

54. Horby P, Lim WS, Emberson JR, Mafham M, Bell JL, Linsell L, et al. Dexamethasone in hospitalized patients with Covid-19 - preliminary report. N Engl J Med. (2020). doi: 10.1056/NEJMoa2021436. [Epub ahead of print].

55. Siemieniuk RA, Bartoszko JJ, Ge L, Zeraatkar D, Izcovich A, Pardo-Hernandez H, et al. Drug treatments for covid-19: living systematic review and network meta-analysis. BMJ. (2020) 370:m2980. doi: 10.1136/bmj.m2980

56. Metzler B, Siostrzonek P, Binder RK, Bauer A, Reinstadler SJ. Decline of acute coronary syndrome admissions in Austria since the outbreak of COVID-19: the pandemic response causes cardiac collateral damage. Eur Heart J. (2020) 41:1852-3. doi: 10.1093/eurheartj/ehaa314

57. De Rosa S, Spaccarotella C, Basso C, Calabrò MP, Curcio A, Filardi PP, et al. Reduction of hospitalizations for myocardial infarction in Italy in the COVID-19 era. Eur Heart J. (2020) 41:2083-8. doi: 10.1093/eurheartj/ehaa610

58. De Filippo O, D’Ascenzo F, Angelini F, Bocchino PP, Conrotto F, Saglietto A, et al. Reduced rate of hospital admissions for ACS during Covid-19 outbreak in Northern Italy. N Engl J Med. (2020) 383:889. doi: 10.1056/NEJMc2009166 
59. Solomon MD, McNulty EJ, Rana JS, Leong TK, Lee C, Sung SH, et al. The Covid-19 pandemic and the incidence of acute myocardial infarction. $N$ Engl J Med. (2020) 383:691-3. doi: 10.1056/NEJMc2015630

60. Garcia S, Albaghdadi MS, Meraj PM, Schmidt C, Garberich R, Jaffer FA, et al. Reduction in ST-segment elevation cardiac catheterization laboratory activations in the United States during COVID-19 pandemic. J Am Coll Cardiol. (2020) 75:2871-2. doi: 10.1016/j.jacc.2020.04.011

61. Xiang D, Xiang X, Zhang W, Yi S, Zhang J, Gu X, et al. Management and outcomes of patients with STEMI during the COVID-19 pandemic in China. J Am Coll Cardiol. (2020) 76:1318-24. doi: 10.1016/j.jacc.2020.06.039

62. Ferreira E, Alves TS, Mourilhe-Rocha R, Lacerda ALI, Albuquerque FN, Spineti PPM, et al. Safety of interventional cardiology procedures in chronic coronary syndrome during the COVID-19 pandemic. Arq Bras Cardiol. (2020) 115:712-6. doi: 10.36660/abc.20200704

63. Piccolo R, Bruzzese D, Mauro C, Aloia A, Baldi C, Boccalatte $M$, et al. Population Trends in rates of percutaneous coronary revascularization for acute coronary syndromes associated with the COVID-19 outbreak. Circulation. (2020) 141:20357. doi: 10.1161/CIRCULATIONAHA.120.047457

64. Mafham MM, Spata E, Goldacre R, Gair D, Curnow P, Bray M, et al. COVID-19 pandemic and admission rates for and management of acute coronary syndromes in England. Lancet. (2020) 396:381389. doi: 10.1016/S0140-6736(20)31356-8

65. Choudry FA, Hamshere SM, Rathod KS, Akhtar MM, Archbold RA, Guttmann OP, et al. High thrombus burden in patients with COVID19 presenting with ST-segment elevation myocardial infarction. J Am Coll Cardiol. (2020) 76:1168-76. doi: 10.1016/j.jacc.2020.07.022

66. Han $Y$, Zeng $H$, Jiang $H$, Yang $Y$, Yuan $Z$, Cheng $X$, et al. CSC expert consensus on principles of clinical management of patients with severe emergent cardiovascular diseases during the COVID-19 epidemic. Circulation. (2020) 141:e8106. doi: 10.1161/CIRCULATIONAHA.120.047011

67. Jing ZC, Zhu HD, Yan XW, Chai WZ, Zhang S. Recommendations from the peking union medical college hospital for the management of acute myocardial infarction during the COVID-19 outbreak. Eur Heart J. (2020) 41:1791-4. doi: 10.1093/eurheartj/ehaa258

68. Xiang D, Huo Y, Ge J. Expert consensus on operating procedures at chest pain centers in China during the coronavirus infectious disease-19 epidemic. Cardiology Plus. (2020) 5:21-32. doi: 10.4103/cp.cp_5_20

69. Sadeghipour P, Talasaz AH, Eslami V, Geraiely B, Vojdanparast M, Sedaghat $\mathrm{M}$, et al. Management of ST-segment-elevation myocardial infarction during the coronavirus disease (2019). (COVID-19) outbreak: Iranian "247" national committee's position paper on primary percutaneous coronary intervention. Catheter Cardiovasc Interv. (2020). doi: 10.1002/ccd.28889. [Epub ahead of print].

70. Zaman S, MacIsaac AI, Jennings GL, Schlaich MP, Inglis SC, Arnold R, et al. Cardiovascular disease and COVID-19: Australian and New Zealand consensus statement. Med J Aust. (2020) 213:182-7. doi: 10.5694/mja2.50714

71. Szerlip M, Anwaruddin S, Aronow HD, Cohen MG, Daniels MJ, Dehghani $\mathrm{P}$, et al. Considerations for cardiac catheterization laboratory procedures during the COVID-19 pandemic perspectives from the society for cardiovascular angiography and interventions emerging leader mentorship (SCAI ELM) members and graduates. Catheter Cardiovasc Interv. (2020) 96:586-97. doi: 10.1002/ccd.28887

72. Mahmud E, Dauerman HL, Welt FGP, Messenger JC, Rao SV, Grines C, et al. Management of acute myocardial infarction during the COVID19 pandemic: a position statement from the society for cardiovascular angiography and interventions (SCAI), the American college of cardiology (ACC), and the American college of emergency physicians (ACEP). J Am Coll Cardiol. (2020) 76:1375-84. doi: 10.1002/ccd.28946

73. Chieffo A, Stefanini GG, Price S, Barbato E, Tarantini G, Karam N, et al. EAPCI position statement on invasive management of acute coronary syndromes during the COVID-19 pandemic. Eur Heart J. (2020) 41:183951. doi: 10.1093/eurheartj/ehaa381

74. Schiavone M, Gobbi C, Biondi-Zoccai G, D’Ascenzo F, Palazzuoli A, Gasperetti A, et al. Acute coronary syndromes and Covid-19: exploring the uncertainties. J Clin Med. (2020) 9:1683. doi: 10.3390/jcm9061683
75. Tam CF, Cheung KS, Lam S, Wong A, Yung A, Sze M, et al. Impact of Coronavirus disease 2019 (COVID-19) outbreak on st-segment-elevation myocardial infarction care in Hong Kong, China. Circ Cardiovasc Qual Outcomes. (2020) 13:e006631. doi: 10.1161/CIRCOUTCOMES.120.006631

76. Stefanini GG, Montorfano M, Trabattoni D, Andreini D, Ferrante G, Ancona $\mathrm{M}$, et al. ST-elevation myocardial infarction in patients with COVID19: clinical and angiographic outcomes. Circulation. (2020) 141:21136. doi: 10.1161/CIRCULATIONAHA.120.047525

77. Armstrong PW, Gershlick AH, Goldstein P, Wilcox R, Danays T, Lambert $\mathrm{Y}$, et al. Fibrinolysis or primary PCI in ST-segment elevation myocardial infarction. N Engl J Med. (2013) 368:1379-87. doi: 10.1056/NEJMoa1301092

78. Nijjer SS, Petraco R, Sen S. Optimal management of acute coronary syndromes in the era of COVID-19. Heart. (2020) 106:1609-16. doi: 10.1136/heartjnl-2020-317143

79. Ibanez B, James S, Agewall S, Antunes MJ, Bucciarelli-Ducci C, Bueno $\mathrm{H}$, et al. (2017). ESC guidelines for the management of acute myocardial infarction in patients presenting with ST-segment elevation: the task force for the management of acute myocardial infarction in patients presenting with ST-segment elevation of the European society of cardiology (ESC). Eur Heart J. (2018) 39:119-77. doi: 10.5603/KP.2018.0041

80. Chinese Society of Cardiology of Chinese Medical Association, Editorial Board of Chinese Journal of Cardiology. 2019 Chinese society of cardiology (CSC) guidelines for the diagnosis and management of patients with STsegment elevation myocardial infarction. Chin J Cardiol. (2019) 47:76683. doi: 10.3760/cma.j.issn.0253-3758.2019.10.003

81. Daviet F, Guervilly C, Baldesi O, Bernard-Guervilly F, Pilarczyk E, Genin A, et al. Heparin-induced thrombocytopenia in severe COVID-19. Circulation. (2020) 142:1875-7. doi: 10.1161/CIRCULATIONAHA.120.049015

82. Falcone M, Russo A, Cangemi R, Farcomeni A, Calvieri C, Barillà $\mathrm{F}$, et al. Lower mortality rate in elderly patients with communityonset pneumonia on treatment with aspirin. J Am Heart Assoc. (2015) 4:e001595. doi: 10.1161/JAHA.114.001595

83. Boyle AJ, Di Gangi S, Hamid UI, Mottram LJ, McNamee L, White G, et al. Aspirin therapy in patients with acute respiratory distress syndrome (ARDS) is associated with reduced intensive care unit mortality: a prospective analysis. Crit Care. (2015) 19:109. doi: 10.1186/s13054-015-0846-4

84. Kor DJ, Carter RE, Park PK, Festic E, Banner-Goodspeed VM, Hinds R, et al. Effect of aspirin on development of ARDS in at-risk patients presenting to the emergency department: the LIPS-A randomized clinical trial. JAMA. (2016) 315:2406-14. doi: 10.1001/jama.2016.6330

85. Gross AK, Dunn SP, Feola DJ, Martin CA, Charnigo R, Li Z, et al. Clopidogrel treatment and the incidence and severity of community acquired pneumonia in a cohort study and meta-analysis of antiplatelet therapy in pneumonia and critical illness. J Thromb Thrombolysis. (2013) 35:147-54. doi: 10.1007/s11239-012-0833-4

86. O’Donoghue ML, Murphy SA, Sabatine MS. The safety and efficacy of aspirin discontinuation on a background of a P2Y(12) inhibitor in patients after percutaneous coronary intervention: a systematic review and meta-analysis. Circulation. (2020) 142:538-45. doi: 10.1161/CIRCULATIONAHA.120.046251

87. Lancellotti P, Musumeci L, Jacques N, Servais L, Goffin E, Pirotte B, et al. Antibacterial activity of ticagrelor in conventional antiplatelet dosages against antibiotic-resistant gram-positive bacteria. JAMA Cardiol. (2019) 4:596-9. doi: 10.1001/jamacardio.2019.1189

88. Sexton TR, Zhang G, Macaulay TE, Callahan LA, Charnigo R, Vsevolozhskaya OA, et al. Ticagrelor reduces thromboinflammatory markers in patients with pneumonia. JACC Basic Transl Sci. (2018) 3:435-49. doi: 10.1016/j.jacbts.2018.05.005

89. Cannon CP, Harrington RA, James S, Ardissino D, Becker RC, Emanuelsson $\mathrm{H}$, et al. Comparison of ticagrelor with clopidogrel in patients with a planned invasive strategy for acute coronary syndromes (PLATO): a randomised double-blind study. Lancet. (2010) 375:283-293. doi: 10.1016/S0140-6736(09)62191-7

90. Ekstrand C, Linder $M$, Cherif $H$, Kieler $H$ Bahmanyar $S$. Increased susceptibility to infections before the diagnosis of immune thrombocytopenia. J Thromb Haemost. (2016) 14:807-14. doi: 10.1111/jth.13267 
91. Gorelik O, Izhakian S, Barchel D, Almoznino-Sarafian D, Tzur I, Swarka M, et al. Prognostic significance of platelet count changes during hospitalization for community-acquired pneumonia. Platelets. (2017) 28:380-6. doi: 10.1080/09537104.2016.1219032

92. Brogly N, Devos P, Boussekey N, Georges H, Chiche A, Leroy O. Impact of thrombocytopenia on outcome of patients admitted to ICU for severe community-acquired pneumonia. J Infect. (2007) 55:13640. doi: 10.1016/j.jinf.2007.01.011

93. Tejera P, Christiani DC. Deconstructing ARDS variability: platelet count, an ARDS intermediate phenotype and novel mediator of genetic effects in ARDS. Semin Respir Crit Care Med. (2019) 40:12-8. doi: 10.1055/s-0039-1683891

94. Washington AV, Esponda O, Gibson A. Platelet biology of the rapidly failing lung. Br J Haematol. (2020) 188:641-51. doi: 10.1111/bjh.16315

95. Park DW, Kwon O, Jang JS, Yun SC, Park H, Kang DY, et al. Clinically significant bleeding with ticagrelor versus clopidogrel in korean patients with acute coronary syndromes intended for invasive management: a randomized clinical trial. Circulation. (2019) 140:186577. doi: 10.1161/CIRCULATIONAHA.119.041766

96. Szummer K, Montez-Rath ME, Alfredsson J, Erlinge D, Lindahl B, Hofmann $\mathrm{R}$, et al. Comparison between ticagrelor and clopidogrel in elderly patients with an acute coronary syndrome: insights from the SWEDEHEART registry. Circulation. (2020) 142:1700-8. doi: 10.1161/CIRCULATIONAHA.120.050645

97. Giustino G, Pinney SP, Lala A, Reddy VY, Johnston-Cox HA, Mechanick JI, et al. Coronavirus and cardiovascular disease, myocardial injury, and arrhythmia: JACC focus seminar. J Am Coll Cardiol. (2020) 76:201123. doi: 10.1016/j.jacc.2020.08.059

98. Rudski L, Januzzi JL, Rigolin VH, Bohula EA, Blankstein R, Patel AR, et al. Multimodality imaging in evaluation of cardiovascular complications in patients with COVID-19: JACC scientific expert panel. J Am Coll Cardiol. (2020) 76:1345-57. doi: 10.1016/j.jacc.2020.06.080

99. Puntmann VO, Carerj ML, Wieters I, Fahim M, Arendt C, Hoffmann J, et al. Outcomes of cardiovascular magnetic resonance imaging in patients recently recovered from Coronavirus disease 2019 (COVID-19). JAMA Cardiol. (2020) 5:1265-73. doi: 10.1001/jamacardio.2020.3557

100. Rajpal S, Tong MS, Borchers J, Zareba KM, Obarski TP, Simonetti $\mathrm{OP}$, et al. Cardiovascular magnetic resonance findings in competitive athletes recovering from COVID-19 infection. JAMA Cardiol. (2020). doi: 10.1001/jamacardio.2020.4916. [Epub ahead of print].

101. Huang L, Zhao P, Tang D, Zhu T, Han R, Zhan C, et al. Cardiac Involvement in Patients Recovered From COVID-2019 Identified Using Magnetic Resonance Imaging. JACC Cardiovasc Imaging. (2020) 13:23309. doi: 10.1016/j.jcmg.2020.05.004

102. Wu Q, Zhou L, Sun X, Yan Z, Hu C, Wu J, et al. Altered lipid metabolism in recovered SARS patients twelve years after infection. Sci Rep. (2017) 7:9110. doi: 10.1038/s41598-017-0 9536-z

103. Zhang XJ, Qin JJ, Cheng X, Shen L, Zhao YC, Yuan Y, et al. In-hospital use of statins is associated with a reduced risk of mortality among individuals with COVID-19. Cell Metab. (2020) 32:176-87.e174. doi: 10.1016/j.cmet.2020. 06.015

104. Hermida N, Balligand JL. Low-density lipoprotein-cholesterol-induced endothelial dysfunction and oxidative stress: the role of statins. Antioxid Redox Signal. (2014) 20:1216-37. doi: 10.1089/ars.201 3.5537

Conflict of Interest: The authors declare that the research was conducted in the absence of any commercial or financial relationships that could be construed as a potential conflict of interest.

Copyright (C) 2021 Liu, Wang, Sun, Teng, Li, Zhou and Yang. This is an open-access article distributed under the terms of the Creative Commons Attribution License (CC $B Y)$. The use, distribution or reproduction in other forums is permitted, provided the original author(s) and the copyright owner(s) are credited and that the original publication in this journal is cited, in accordance with accepted academic practice. No use, distribution or reproduction is permitted which does not comply with these terms. 